\title{
Sistem Informasi Penjualan dan Persediaan Barang Dagang Pada Perusahaan Hakasima Kota ternate
}

\author{
Novita Burhan ${ }^{1}$, Arifandy Mario Mamonto ${ }^{2}$ \\ ${ }^{1}$ Program Studi Komputerisasi Akuntansi, ${ }^{2}$ Teknik Komputer \\ Politeknik Sains dan Teknologi Wiratama Maluku Utara \\ novita_b@yahoo.com
}

\begin{abstract}
Abstrak
Penelitian ini bertujuan untuk merancang sistem informasi penjualan dan persediaan barang dagang pada Perusahaan Hakasima Kota Ternate, Metode pengumpulan data yang digunakan adalah observasi, wawancara dan dokumentasi kepada pihak perusahaan, Rancangan analisis sistem yang lama dan analisis sistem diusulkan menggunakan model Flowchart diagram serta hasil rancangan sistem menggunakan model $U M L$, Bahasa pemrograman yang digunakan menggunakan Borland Delphi 7 serta Microsoft Acces sebagai database, hasil peniltian ini dapat mempercepat pengelolaan data barang serta mempermudah dalam pembuatan catatan transaksi penjualan Barang serta pembuatan laporan pada sistem secara cepat
\end{abstract}

\section{Kata kunci: Sistem Informasi, Penjualan, Persediaan, Borland Delphi 7}

\section{Abstract}

This research aims to design an information system sales and merchandise inventory on company Hakasima city of Ternate, Data collection methods used are observation, interview and documentation to the company, The design of the system analysis and the analysis of the proposed system using model and draft results diagram Flowchart system using UML models, The programming language used to use Borland Delphi 7 as well as Microsoft Access as database, the results of this peniltian can speed up data management stuff as well as ease in the manufacture and sale of goods transaction records the creation of reports on the system quickly

\section{Keywords: Information Systems, Sales, Inventory, Borland Delphi 7}

\section{PENDAHULUAN}

Pada era kemajuan teknologi seperti sekarang ini, manusia dapat melakukan pertukaran informasi dengan cepat walaupun dipisahkan jarak yang jauh tempat kita berada. Hal ini dimungkinkan karena semakin berkembangnya teknologi informasi yang bertujuan untuk memudahkan pekerjaan manusia dalam megelola data pada organisasi maupun instansi salah satu dalam megelola data transaksi penjualan dan persediaan

Menurut Mulyadi (2001:78) Dalam melakukan penjualan, adanya suatu peralihan hak, pemindahan hak kepemilikan atas barang dan jasa dari pihak penjual kepada pihak pembeli yang disertai penyerahan imbalan dari pihak penerima barang atau jasa sebagai timbal balik atas penyerahan tersebut. sedangkan persediaan adalah suatu aktiva yang meliputi barangbarang milik perusahaan dengan maksud untuk dijual dalam suatu periode yang normal, atau sediaan barang-barang yang masih dalam pengerjaan atau proses produksi, ataupun sediaan bahan baku yang menunggu penggunaannya dalam suatu proses produksi.

Perusahan Hakasima merupakan perusahaan lokal yang bergerak dalam bidang perdagangan dan jasa yang menyediakan kebutuhan pokok dan 
kebutuhan sehari-hari. dengan pelayanan dan sasaran pasar adalah konsumen semua kalangan masyarakat. Dalam mengelola data transaksi dan persediaan pada perusahaan Hakasima masih menggunakan media yang manual dimana data persediaan dan transaksi dicatat secara satu persatu pada dokumen dan dijumlahkan pada kalkulator sehingga pengelolaan tersebut dianggap kurang efektif

berdasarkan hasil uraian masalah maka dibutuhkan media yang terkomputerisasi yang mempunyai bahasa pemrograman yang dapat diolah data persediaan dan transaksi secara otomatis pada satu layar secara cepat serta tersimpan pada database

\section{Rumusan Masalah}

Data transaksi dan persediaan pada perusahaan Hakasima masih menggunakan media yang manual dimana data persediaan dan transaksi dicatat secara satu persatu pada dokumen dan dijumlahkan pada kalkulator, maka dapat dirumuskan masalah sebagai berikut "bagaimana merancang sistem informasi penjualan dan persediaan barang dagang pada Perusahaan Hakasima Kota Ternate"

\section{Tujuan Penelitian}

Penilitian ini bertujuan untuk merancang sistem informasi penjualan dan persediaan barang dagang pada Perusahaan Hakasima Kota Ternate

\section{Manfaat Penelitian}

1. Penelitian ini memberikan kemudahan bagi konsumen dan pelanggan perusahaan Hakasima Kota Ternate.

2. Sistem informasi dapat meningkatkan penjualan dan persediaan barang Hakasima Kota Ternate.

\section{Tinjauan Pustaka}

Menurut penelitian M. Sadam ABD Azis Nur, Indah Uly Wardati dengan judul Perancangan sistem informasi penjualan kaos pada UD. Gojek bertujuan Menghasilkan Perancangan sistem informasi penjualan T-Shirt pada UD. Gojek Pacitan. Peniltian menggunakan model rancangan diagram Diagram Flow Data (DFD), hasil dari penelitian tersebut dapat memberikan gambaran proses penjualan, pembelian ketepatan dalam pemriksaan persediaan dan laporan penjualan yang terkomputerisasi hasil dari peniltian memberi gambaran kepeda pihak UD. Gojek tentang pengolahan data pembelian, penjualan, pengontrolan barang, persediaan barang maupun pembuatan laporan, seperti laporan penjualan, pembelian, laba rugi penjualan dan laporan persedian barang.

Syukri Ali, Arisandy Ambarita dalam penelitian yang berjudul sistem Informasi data barang Inventaris berbasis web pada kejaksaan negeri ternate bertujuan Mengetahui informasi tentang data barang inventaris kantor dalam mendukung kinerja dan pelayanan pada Kejaksaan Negeri Ternate, Sistem tersebut dirancang menggunakan bahasa pemrograman $H T M L$, $P H P$, serta database $M y S Q L$ dan menghasilkan kesimpulan sistem tersebut Dapat membantu pegawai di Kantor Kejaksaan Negeri Ternate dalam melaksanakan pendataan barang inventaris.

Berdasarkan kedua uraian peniltian diatas maka perbandingan dengan peniltian ini adalah pada peniltian ini menggunakan model rancangan UML dengan bahasa Pemrograman Delphi 7 dan Microsoft Acces sebagai databasenya sedangkan penelitian diatas masing-masing mengelola data transaksi dengan menggunakan bahasa pemrograman $H T M L, P H P, M Y S Q L$ sebagai 
database serta model rancangan menggunakan Diagram Flow Data (DFD)

\section{Pengertian Sistem}

Menurut Sutarman (2012:5) sistem adalah kumpulan elemen yang saling berhubungan dan saling berinteraksi dalam satu kesatuan untuk menjalankan suatu proses pencapaian suatu tujuan utama.

Menurut Jemmy (2008:9) sistem adalah hubungan satu unit dengan unit-unit lainnya yang saling berhubungan satu sama lainnya dan yang tidak dapat dipisahkan serta menuju satu kesatuan dalam rangka mencapai tujuan yang telah ditetapkan. Apabila suatu unit macet atau terganggu, unit lainnya pun akan terganggu untuk mencapai tujuan yang telah ditetapkan tersebut

\section{Elemen Sistem}

Menurut Yakub (2012:3) tidak semua sistem memiliki kombinasi elemen-elemen yang sama, tetapi susunan dasarnya sama.

Elemen-elemen yang terdapat dalam sistem ditandai dengan adanya:

a. Tujuan

Tujuan ini menjadi motivasi yang mengarahkan pada sistem, karena tanpa tujuan yang jelas sistem menjadi tak terarah dan tak terkendali.

b. Masukan

Masukan (input) sistem adalah segala sesuatu yang masuk ke dalam sistem dan selanjutnya menjadi bahan untuk diproses. Masukan dapat berupa hal-hal berwujud maupun yang tidak berwujud. Masukan berwujud adalah bahan mentah, sedangkan yang tidak berwujud adalah informasi.

c. Proses

Proses merupakan elemen yang bertugas melakukan perubahan atau transformasi dari masukan / data menjadi keluaran / informasi yang berguna dan lebih bernilai.

d. Keluaran

Keluaran (output) merupakan hasil dari input yang sudah dilakukan pemerosesan sistem dan keluaran dapat menjadi masukan untuk subsistem lain.

e. Batasan

Batasan (boundary) sistem adalah pemisah antara sistem dan daerah diluar sistem. Selain itu juga sebagai batasan - batasan dari tujuan yang akan dicapai oleh sistem. Batas sistem menentukan konfigurasi, ruang lingkup, atau kemampuan sistem.

f. Umpan Balik

Umpan balik ini digunakan untuk mengendalikan masukan maupun proses. Umpan balik juga bertugas mengevaluasi bagian dari output yang dikeluarkan. Tujuannya untuk mengatur agar sistem berjalan sesuai dengan tujuan.

\section{Sistem Informasi}

Menurut Mulyadi (2010:5) Sistem informasi adalah jaringan prosedur yang dibuat menurut pola yang terpadu untuk melaksanakan kegiatan-kegiatan pokok perusahaan sedangkan prosedur adalah suatu urutan kegiatan klerikal, biasanya melibatkan beberapa orang dalam satu departemen atau lebih yang dibuat untuk menjamin penanganan secara seragam transaksi perusahaan yang terjadi secara berulang-ulang.

Menurut Susanto (2008:22) Sistem informasi adalah kumpulan/group dari sub sistem/bagian/komponen apapun baik phisik ataupun non phisik yang saling berhubungan satu sama lain dan bekerja sama secara harmonis untuk mencapai satu tujuan tertentu 


\section{Penjualan}

Menurut Mulyadi (2001:78) Dalam melakukan penjualan, adanya suatu peralihan hak, pemindahan hak kepemilikan atas barang dan jasa dari pihak penjual kepada pihak pembeli yang disertai penyerahan imbalan dari pihak penerima barang atau jasa sebagai timbal balik atas penyerahan tersebut. Beberapa jenis penjualan, yaitu:

\section{a. Trade Selling}

Terjadi bila produsen dan pedagang besar memperbolehkan pengecer untuk mendistribusikan produk-produk mereka.

\section{b. Missionery Selling}

Dalam hal ini penjualan berusaha ditingkatkan dengan mendorong pembeli untuk membeli barang-baranag dari penyalur yang ditunjuk oleh perusahaan.

c. Technical Selling

Peningkatan dan pemberian saran-saran dan nasehat kepada pembeli.

d. New Bussiness Selling

Berusaha membuat transaksi baru dengan mengubah calon pembeli menjadi pembeli.

e. Responsive Selling

Penjualan dimana setiap tenaga penjual diharapkan dapat memberikan reaksi terhadap permintaan pembeli

\section{Persediaan Barang}

Persediaan adalah suatu aktiva yang meliputi barang-barang milik perusahaan dengan maksud untuk dijual dalam suatu periode yang normal, atau sediaan barangbarang yang masih dalam pengerjaan atau proses produksi, ataupun sediaan bahan baku yang menunggu penggunaannya dalam suatu proses produksi. (Mulyadi, 2001:78)
Pada dasar sediaannya mempermudah atau memperlancar jalannya operasi perusahaan pabrik yang dilakukan secara berturut-turut untuk memproduksi barangbarang serta menyampaikannya kepada pelanggan atau konsumen. Adapun alasannya diadakannya sediaan oleh suatu perusahaan adalah karena:

a. Dibutuhkannya waktu untuk menyelesaikan operasi produksi untuk memindahkan produk dari suatu tingkat proses yang lain, yang disebut dalam proses dan pemindahan.

b. Alasan organisasi untuk memungkinkan suatu unit atau bagian membuat jadwal operasinya secara bebas tidak tergantung dari yang lainnya.Dalam perusahaan industri sediaan barang yang dimiliki terdiri dari beberapa jenis yang berbeda. Masing-masing jenis diberi nama tersendiri agar dapat menunjukkan macam sediaan yang dimiliki, sediaan bahan baku, sediaan bahan penolong, sediaan barang dalam proses dan sediaan bahan jadi.

Suatu perusahaan perlu menggunakan sistem sediaan secara komputerisasi untuk memudahkan dalam mengetahui sediaan barang dalam jumlah besar dan beraneka ragam, serta menentukan sediaan maksimum dan minimum untuk setiap macam barang dalam suatu jangka waktu tertentu.

\section{Borland Delphi 7}

Borland atau dikenal dengan delphy adalah paket bahasa pemograman yang bekerja dalam sistem operasi windows. Delphy merupakan bahasa pemrograman yang mempunyai cakupan kemampuan yang luas dan sangat canggih karena 
sebagian aplikasi dibuat menggunakan delphy, termasuk aplikasi untuk mengolah teks, grafik, angka, database, dan aplikasi web. M Agus J.Alam (2003).

1. Project

Project merupakan sekumpulan form, unit, dan beberapa hal lain dalam program aplikasi, file utama project disimpan dalam file yang berakhiran pada saat dijalankan, file project ini selalu dikomunikasikan menjadi file yang dapat dilaksanakan.

2. Form

Form merupakan suatu yang dipakai sebagai tempat suatu program aplikasi form membentuk jendelah dan dapat dibayangkan sebagai kertas atau meja kerja yang digambarkan atau dicatat, object-object lain sebagai media tata letak dalam mengatur posisi intern dari tampilan program.

3. Unit

Modul kode program suatu project mungkin mempunyai suatu unit atau lebih, dalam delphy ada unit yang terpisah dari form yang sebut unit program, setiap kali dibuat suatu form maka otomatis pula disebut suatu unit

\section{Pengertian Basis Data (Database)}

Menurut Indrajani (2015:70), basis data adalah kumpulan data yang saling berhubungan secara logis dan didesain untuk mendapatkan data yang dibutuhkan oleh suatu organisasi

\section{Microsoft Acces}

Microsoft Acces adalah suatu piranti lunak dari Microsoft Corporation yang membantu proses pembuatan database Stevan (2007:72)

Microsoft Acces salah satu pengolah database termudah dan handal, produk Microsoft walaupun dalam penerapan program berorientasi objek mengalami kesulitan tetapi Microsoft Acces tercepat dan termudah dalam membuat program aplikasi bisnis Supardi (2006:7)

\section{Use Case Diagram}

Rosa dan M. Shalahudin (2014:155), use case atau diagram use case merupakan pemodelan untuk kelakuan (behavior) sistem informasi yang akan dibuat. Use case mendeskripsikan sebuah interaksi antara satu atau lebih aktor dengan sistem informasi yang akan dibuat. Secara kasar, use case digunakan untuk mengetahui fungsi apa saja yang ada di dalam sebuah sistem informasi dan siapa saja yang berhak menggunakan fungsi-fungsi itu

\section{Activity Diagram}

Rosa dan M. Shalahudin (2014:161), diagram aktivitas atau activity diagram menggambarkan workflow (aliran kerja) atau aktivitas dari sebuah sistem atau proses bisnis atau menu yang ada pada perangkat lunak. Yang perlu di perhatikan disini adalah bahwa diagram aktivitas menggambarkan aktivitas sistem bukan apa yang dilakukan aktor, jadi aktivitas yang dapat dilakukan oleh sistem

\section{Sequance Diagram}

Rosa dan M. Shalahudin (2014:165), diagram sekuen menggambarkan kelakuan objek pada use case dengan mendeskripsikan waktu hidup objek dengan massage yang dikirimkan dan diterima antar objek. Oleh karena itu untuk menggambarkan diagram sekuen maka harus diketahui objek-objek yang terlibat dalam sebuah use case beserta metodemetode yang dimiliki kelas yang diinstansiasi menjadi objek itu.

\section{METODE PENELITIAN}


Metode pengumpulan data yang digunakan dalam penelitian ini adalah sebagai berikut:

a. Observasi, teknik ini mendeskripsikan secara rinci mengenai hasil pengamatan dari kegiatan operasional sehari-hari yang berlangsung di perusahaan tersebut, partisipasi yang terlibat dan interaksi yang terjadi antara sistem dan partisipasi

b. Wawancara, teknik ini digunakan untuk mendapatkan data primer melalui wawancara dengan narasumber, tujuannya adalah untuk mengetahui kebutuhan pengguna.

c. Dokumentasi, teknik ini digunakan untuk mengumpulkan dokemundokumen yang berkaitan dengan masalah penjualan dan penyediaan barang.

\section{Bahan dan Alat}

Bahan dan alat merupakan variabel terpenting dalam kegiatan penelitian ini karena untuk memeksimalkan pengembangan Sistem Informasi penjualan dan persedian Barang Dagang Pada Perusahaan Hakasima.

a. Hardware

1. Processor INTEL

2. Mainboard Intel

3. Ram 2 GB.

4. Hardisk $500 \mathrm{~GB}$.

5. LCD Toshiba C640 D.

6. Printer Canon Pixma iP 2770.

7. Keyboard

b. Software.

1. Sistem operasi windows 7 ultimate

2. Microsoft Office Visio 2007 merancang Uml

3. Microsoft Office 2007 membuat Laporan Hasil

4. Microsoft Acces 2007 sebagai Database
5. Bahasa pemograman Borland Delphi 7

\section{Alur Penilitian}

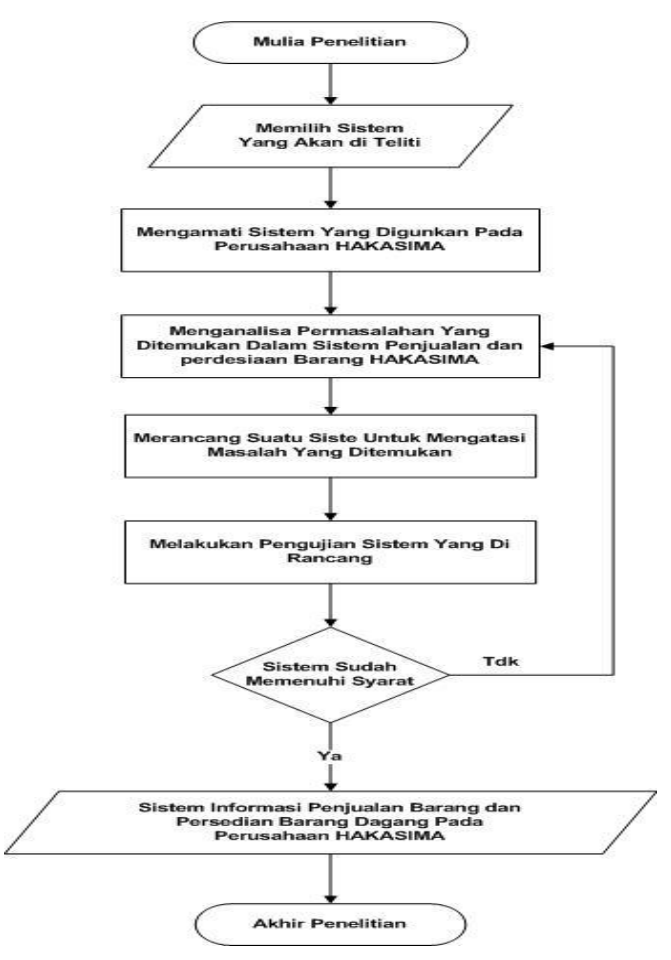

Gambar 1. Alur Penilitian

\section{ANALISIS DAN PERANCANGAN}

Analisis dan perancangan merupakan tahapandalam pengembangan sistem dimana sistem akan dilakukan identifikasi kekuarangan dengan melkukan analisa terhadap sistem tersebut dan dari hasil tersebut dapat dirancang model usulan sistem yang baru

\section{Analisis Sistem yang berjalan}

Analisa sistem yang berjalan merupakan tahapan dalam analisa sistem dimana sistem akan diidentifikasi dengan membuat rancangan analisa menggunakan model diagram tertentu, berikut merupakan gambar diagram analisa sistem yang berjalan pada perusahaan Hakasima ternate 


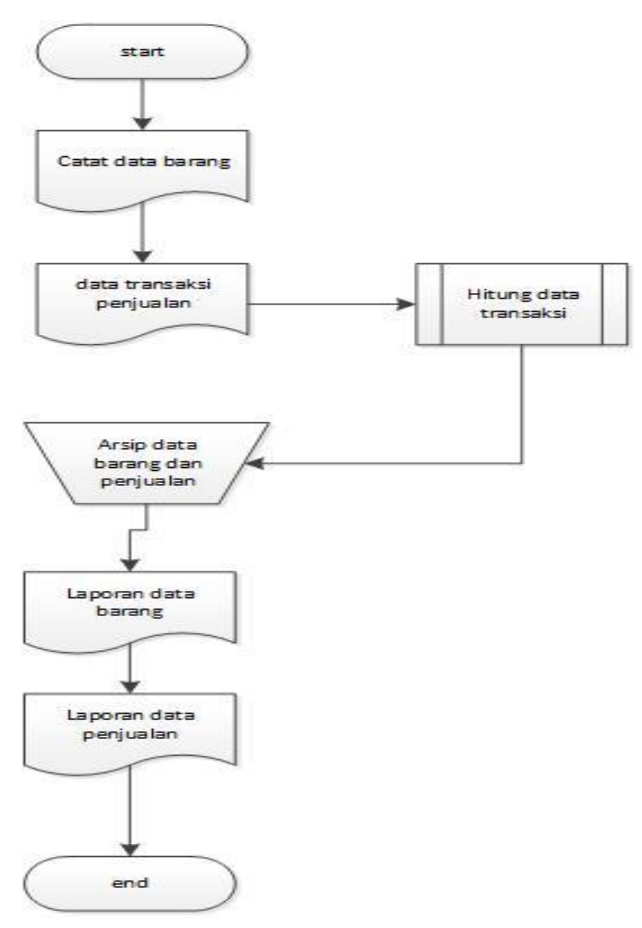

Gambar 2. Analisis Sistem berjalan

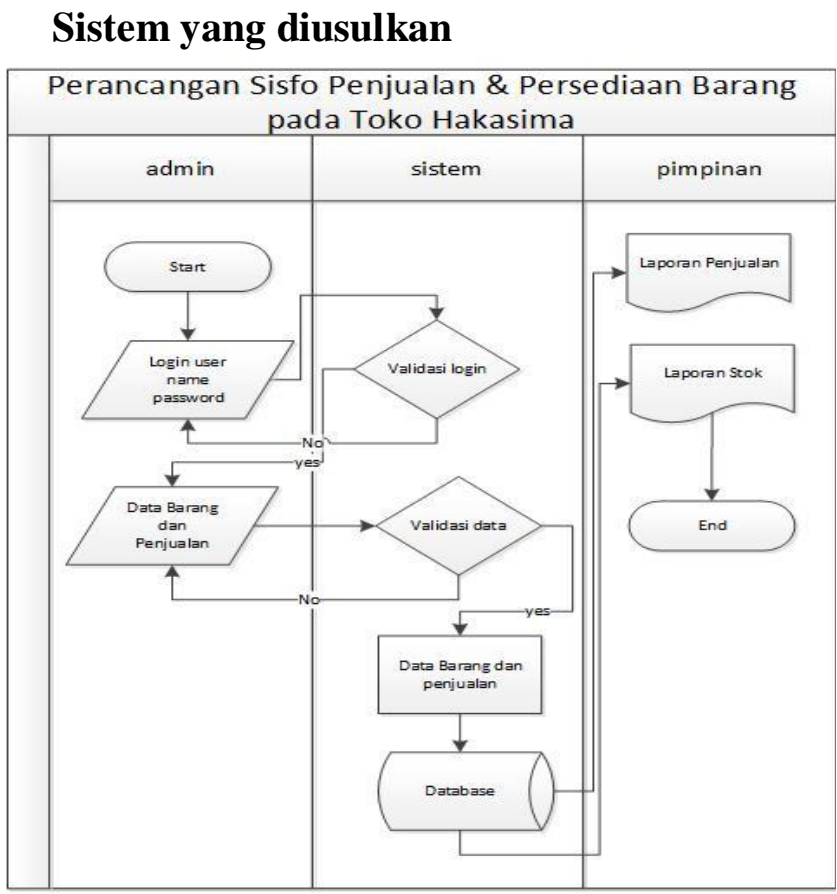

Gambar 3. Analisis Sistem yang diusulkan

\section{Use Case}

Berikut merupakan hasil rancangan use case sistem pada Hakasima Kota Ternate:

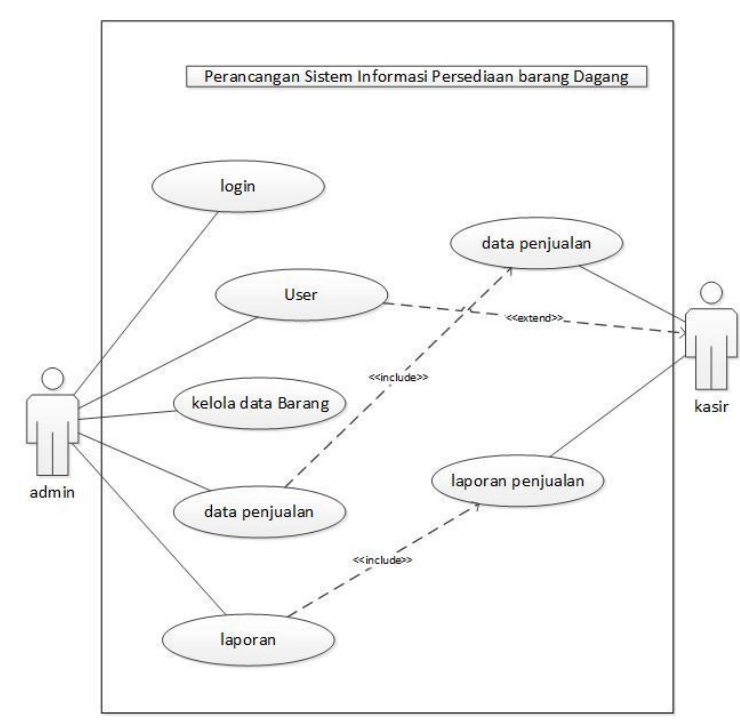

Gambar 4. Use Case

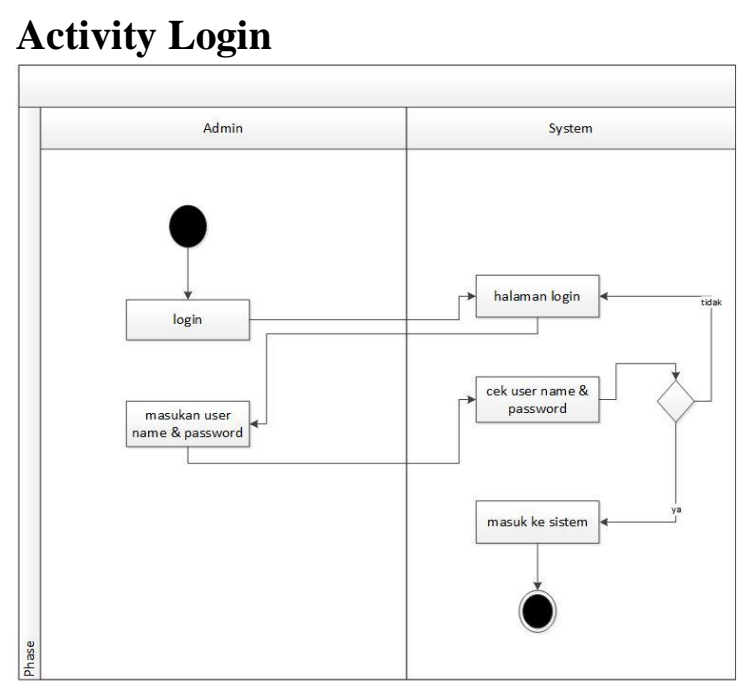

Gambar 5. Activity Login

\section{Activity Admin Kelola data Barang}

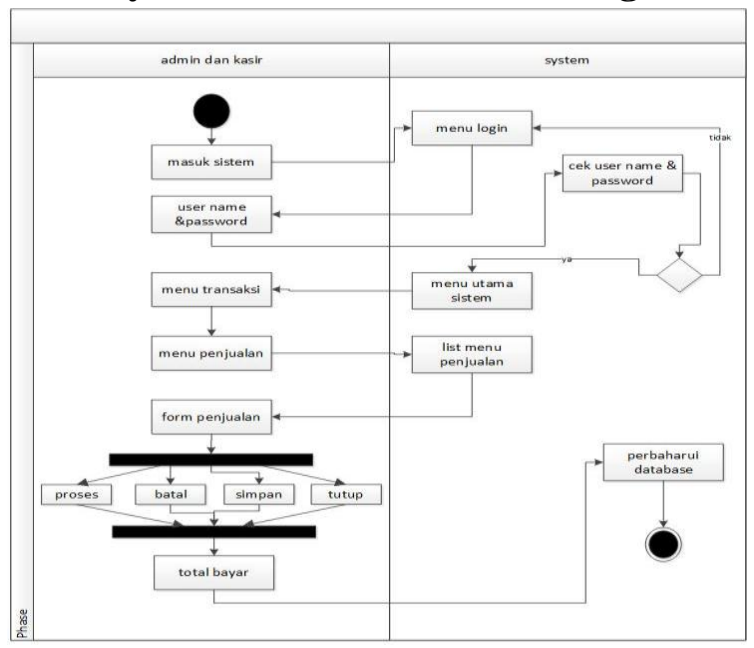

Gambar 6. Activity admin kelola data barang 
Activity Admin Kelola Transaksi

\section{Penjualan}

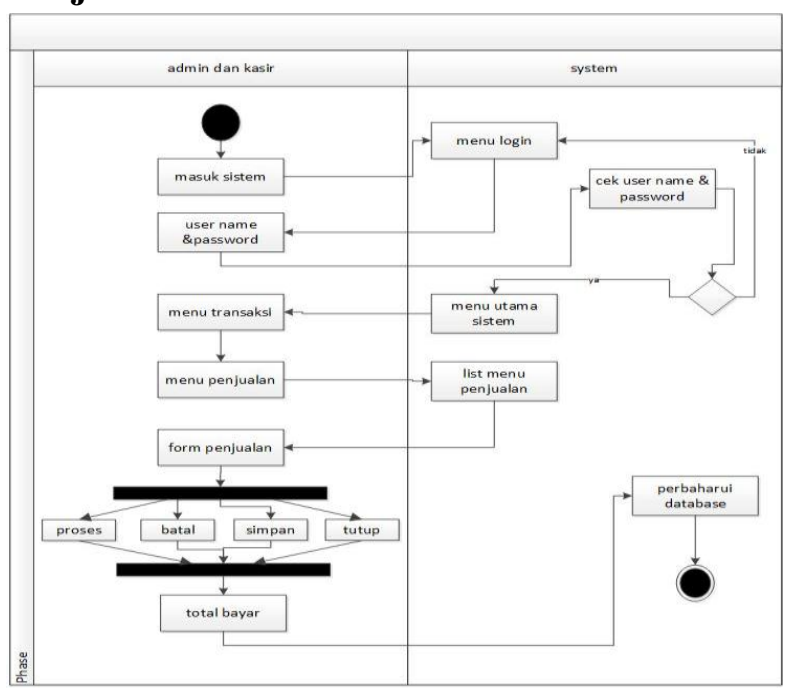

Gambar 7. Admin Kelola Transaksi penjualan

\section{Admin Kelola Data Laporan}

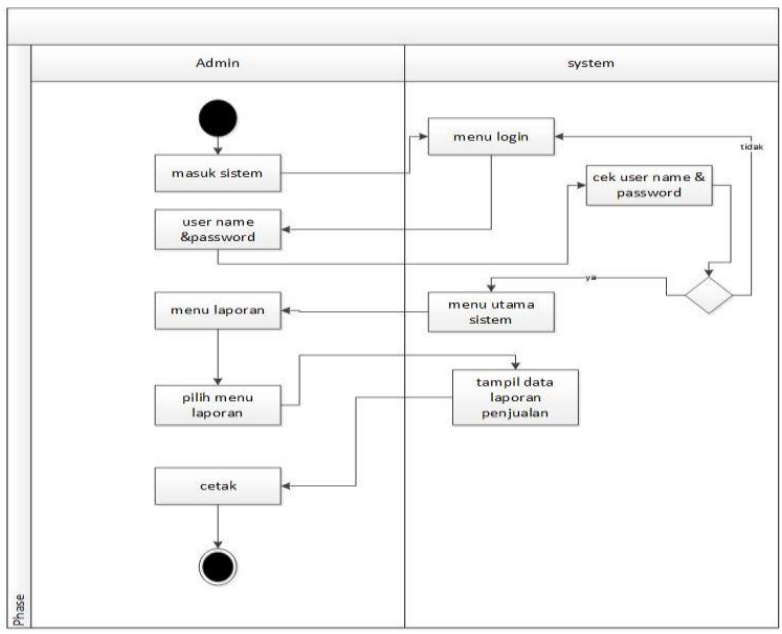

Gambar 8. Admin Kelola Data Laporan

\section{Diagram Sequance Login}

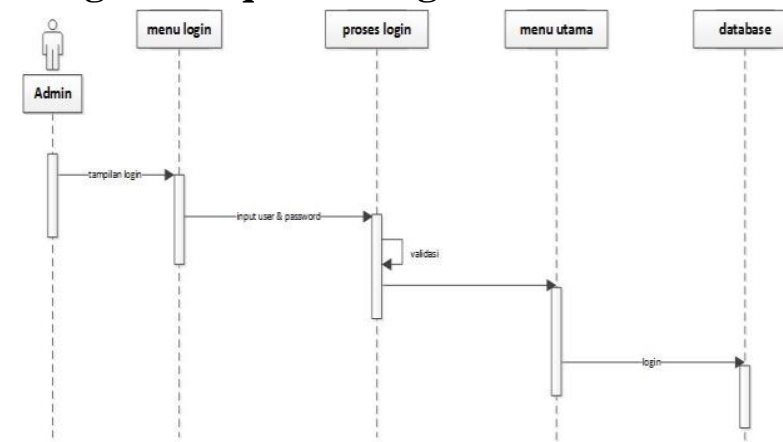

Gambar 9. Diagram Sequance Login
Diagram Sequance Kelola Data Barang

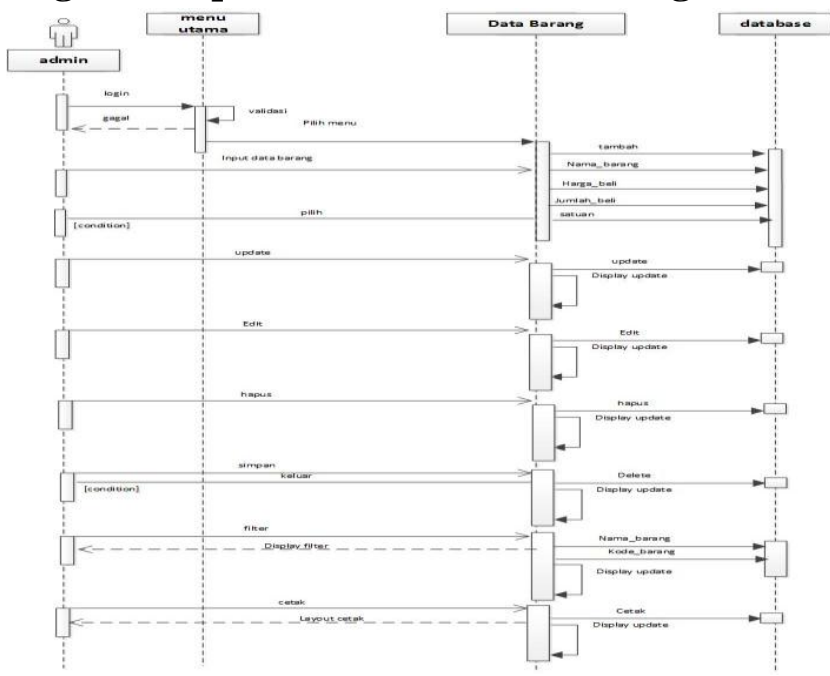

Gambar 10. Sequance Kelola data barang

\section{Sequance Kelola data Transaksi}

Penjualan

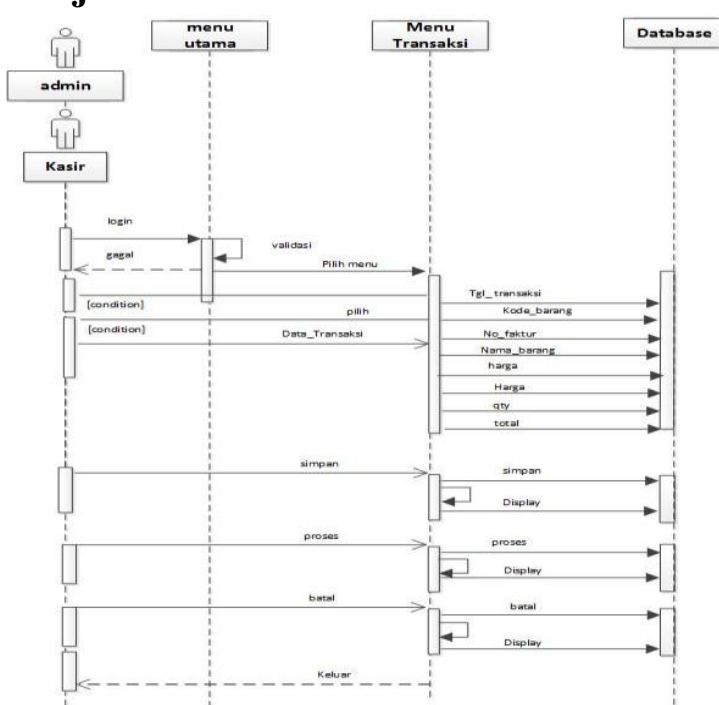

Gambar 11. Sequance Kelola data

Transaksi Penjualan

\section{Sequance Admin Kelola Data Laporan}

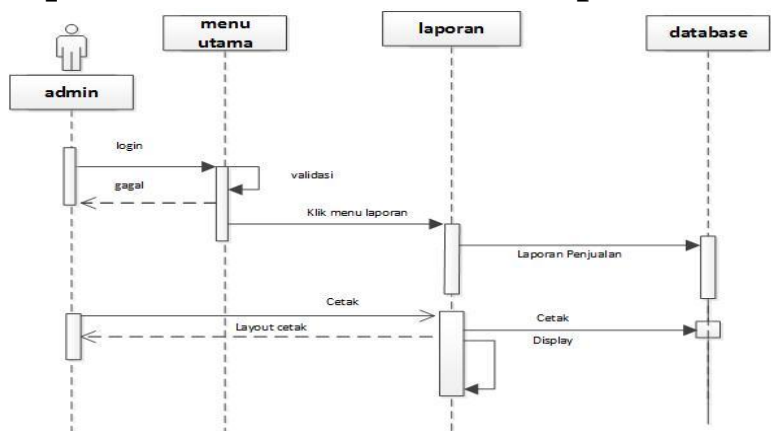

Gambar 12. Sequance Admin Kelola

Laporan 
Class Diagram

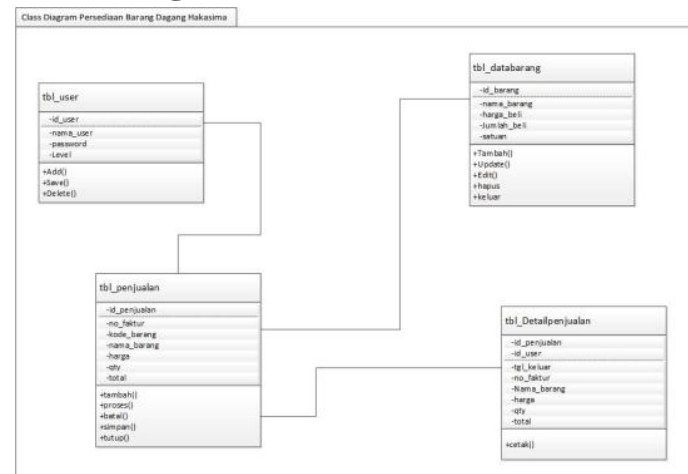

Gambar 13. Class Diagram

Struktur Menu Sistem

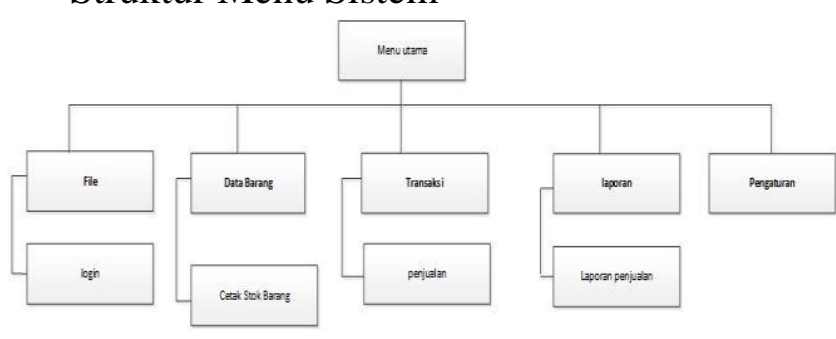

Gambar 14. Struktur Menu Sistem

\section{Rancangan Layout Menu}

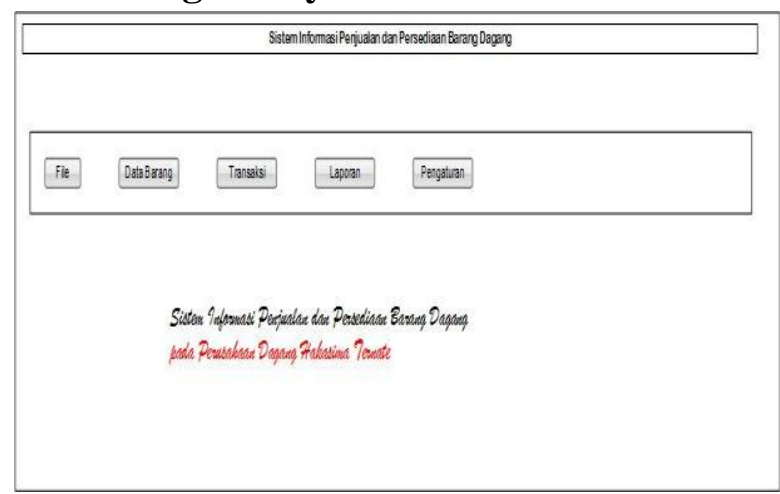

Gambar 15. Rancangan Layout Menu Sistem

\section{Rancangan Tabel Sistem}

Tabel 1. Tbl_Admin

\begin{tabular}{|l|l|l|l|l|}
\hline No & Nama Field & Type & Lenght & Keterangan \\
\hline 1 & Id_user & text & 8 & Primary_key \\
\hline 2 & Nama & text & 10 & \\
\hline 3 & Password & int & 10 & \\
\hline 4 & level & text & & \\
\hline
\end{tabular}

\section{Tabel 2. Data_barang}

\begin{tabular}{|l|l|l|l|l|}
\hline No & Nama Field & Type & Lenght & Keterangan \\
\hline 1 & kode_barang & Number & 6 & Primary_key \\
\hline 2 & Nama_brg & Text & 10 & \\
\hline
\end{tabular}

\begin{tabular}{|l|l|l|l|l|}
\hline 3 & Harga_beli & Number & & \\
\hline 4 & Jumlah_beli & Number & & \\
\hline 5 & satuan & Number & & \\
\hline
\end{tabular}

Tabel 3. Transaksi_penjualan

\begin{tabular}{|l|l|l|l|l|}
\hline No & Nama Field & Type & Lenght & Keterangan \\
\hline 1 & Id_penjualan & Text & 10 & Primary_key \\
\hline 2 & No_faktur & Number & 6 & \\
\hline 3 & kode_barang & Text & 5 & \\
\hline 4 & nama_barang & Text & 6 & \\
\hline 5 & Harga & number & 10 & \\
\hline 10 & Qty & number & 5 & \\
\hline 11 & Total & number & 20 & \\
\hline
\end{tabular}

Tabel 4. Detail_penjualan

\begin{tabular}{|l|l|l|l|l|}
\hline No & Nama Field & Type & Lenght & Keterangan \\
\hline 1 & Id_penjualan & Text & 10 & Primary_key \\
\hline 2 & Id_user & Text & 2 & \\
\hline 3 & Tgl_keluar & Date & & \\
\hline 4 & No_faktur & Number & 5 & \\
\hline 5 & Nama_barang & Text & 6 & \\
\hline 6 & Harga & number & 10 & \\
\hline 7 & Qty & number & 7 & \\
\hline 8 & Total & number & 20 & \\
\hline
\end{tabular}

\section{IMPLEMENTASI DAN PEMBAHASAN}

\section{Tampilan Data User}

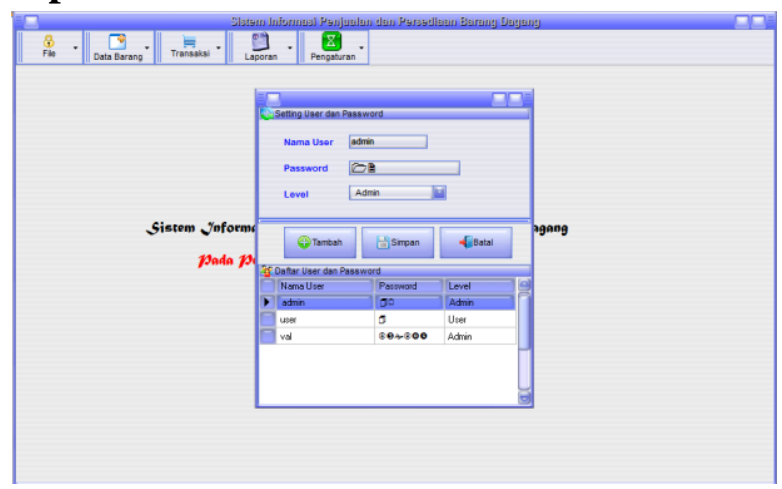

Gambar 16. Tampilan Data User

\section{Tampilan Menu Data Barang}

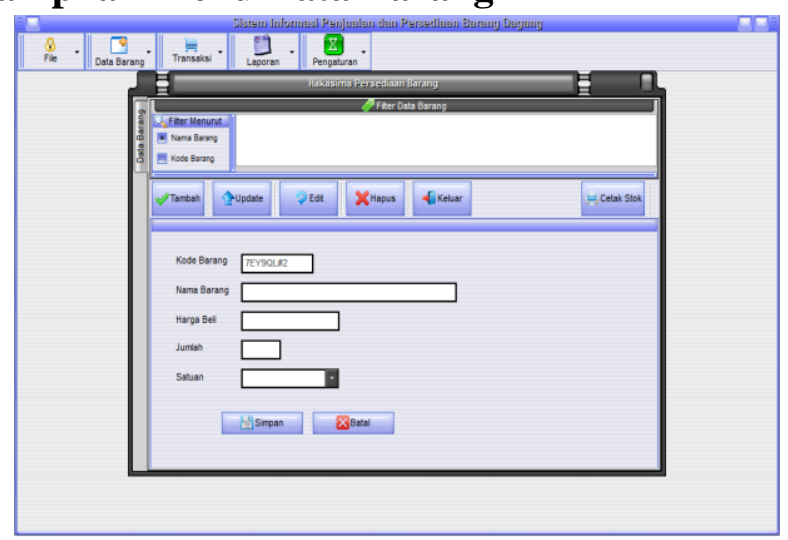

Gambar 17. Tampilan Data barang 
Tampilan Menu Tansaksi Penjualan

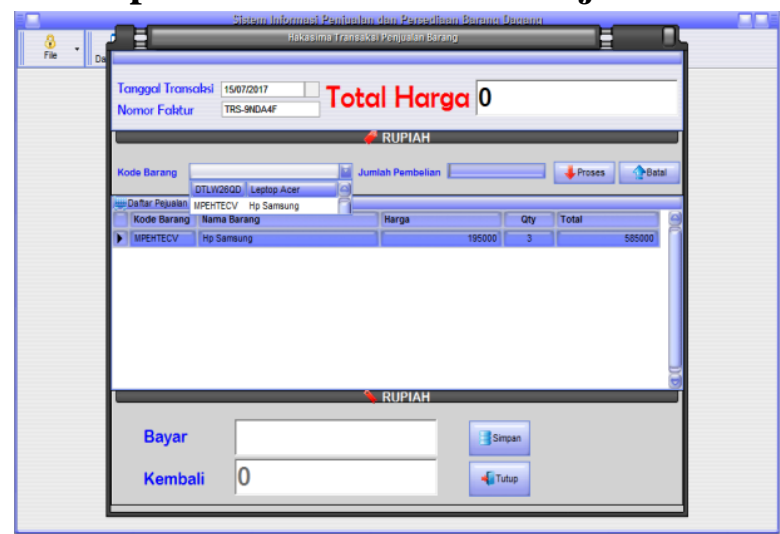

Gambar 18. Tampilan Transaksi Penjualan

\section{Tampilan Menu Laporan}

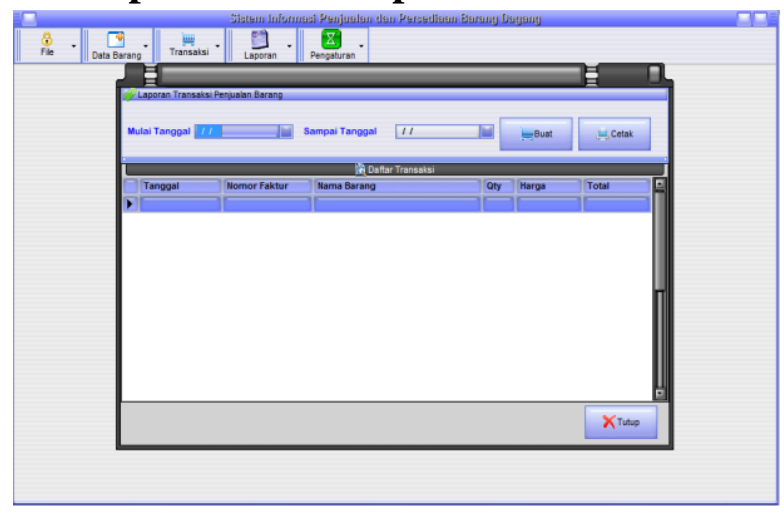

Gambar 19. Tampilan menu Laporan

\section{Pengujian Sistem}

Tabel 5. Pengujian sistem Blackbox

\begin{tabular}{|c|c|c|c|}
\hline No & Nama Modul & $\begin{array}{l}\text { Jenis Unit Yang di } \\
\text { Uji }\end{array}$ & $\begin{array}{r}\text { Hasil } \\
\text { Test }\end{array}$ \\
\hline \multirow[t]{3}{*}{1} & \multirow{3}{*}{$\begin{array}{l}\text { Form menu } \\
\text { Login }\end{array}$} & Username & Sukses \\
\hline & & Password & Sukses \\
\hline & & Level & Sukses \\
\hline \multirow[t]{5}{*}{2} & \multirow[t]{5}{*}{ Menu Utama } & File & Sukses \\
\hline & & Data Barang & Sukses \\
\hline & & Transaksi & Sukses \\
\hline & & Laporan & Sukses \\
\hline & & Pengaturan & Sukses \\
\hline \multirow[t]{13}{*}{3} & \multirow[t]{13}{*}{ Data Barang } & Kode_barang & Sukses \\
\hline & & Nama_barang & Sukses \\
\hline & & Harga_beli & Sukses \\
\hline & & Jumlah & Sukses \\
\hline & & satuan & Sukses \\
\hline & & Filter menurut & Sukses \\
\hline & & Tambah & Sukses \\
\hline & & update & Sukses \\
\hline & & edit & Sukses \\
\hline & & hapus & Sukses \\
\hline & & keluar & Sukses \\
\hline & & cetak & Sukses \\
\hline & & Simpan & Sukses \\
\hline
\end{tabular}

\begin{tabular}{|c|c|c|c|}
\hline & & batal & Sukses \\
\hline \multirow[t]{9}{*}{4} & \multirow[t]{9}{*}{ Transaksi } & Tgl_transaksi & Sukses \\
\hline & & No_faktur & Sukses \\
\hline & & Kode_barang & Sukses \\
\hline & & Jumlah_pembelian & Sukses \\
\hline & & Proses & Sukses \\
\hline & & Batal & Sukses \\
\hline & & Total & Sukses \\
\hline & & Simpan & Sukses \\
\hline & & Tutup & Sukses \\
\hline \multirow[t]{4}{*}{5} & \multirow[t]{4}{*}{ Laporan } & Dari_tanggal & Sukses \\
\hline & & Sampai_tanggal & Sukses \\
\hline & & cetak & Sukses \\
\hline & & tutup & Sukses \\
\hline
\end{tabular}

\section{KESIMPULAN}

Setelah dilakukan implementasi dan pembahasan sebelumnya, maka dapat disimpulakn:

1. Sistem ini dapat mempercepat proses kerja karyawan dalam mengelola informasi data barang.

2. Mempermudah dalam pembuatan catatan transaksi penjualan Barang serta pembuatan laporan pada sistem secara cepat.

\section{Saran}

Dari hasil kesimpulan dalam penelitian ini dapat disarankan sebagai berikut

1. Perlu adanya transaksi pembelian barang pada sistem agar dapat mengontrol laporan persediaan yang di beli dari supplier

2. Pada Sistem memerlukan tambahan item jenis atau kategori barang dalam mengelola data barang yang akan di gunakan nanti

\section{DAFTAR PUSTAKA}

Agus Saputra (2007) Triik Membuat Sistem \& Konsep Dasar HTML, ANDI Yogjakarta

A., S., Rosa \& Shalahuddin, M. (2013). Rekayasa Perangkat Lunak Terstruktur Dan Berorientasi Objek. Bandung. Informatika. 
Imam Heryanto (2012) Modul Pemograman Web HTML, PHP, MySQL. Informatika. Bandung.

Indrajani. 2015. Database Design (Case Study All in One). sutarJakarta: PT Elex Media Komputindo

Jemmy (2008) Sistem Informasi Manajemen Pemahaman dan Aplikasi,

Jogiyanto (2009) Analisis Dan Desain Sistem Informasi. Yogyakarta: Penerbit Graha Ilmu

KadirAbdul (2008) Dasar Pemrograman Web Dinamis Menggunakan PHP Yogyakarta, ANDI.

Alam, M. Agus J. 2005. Belajar Sendiri Pemrograman Database Borland Delphi dalam SQL Server 7.0 dan 2005. Jakarta: PT. Elex Media Komputindo

Mulyadi (2010) Sistem Akuntansi. Jakarta: Salemba Empat

Meilan Anastasia M (2013) PHP + JQUERY Berbasis Linux dan Windows LokoMedia, Yogjakarta

Mulyanto Agus (2009) Sistem Informasi konsep \& Aplikasi, Yogjakarta : Pustaka Pelajar

Muharto \& A. Ambarita (2016). Metode Penelitian Sistem Informasi: Mengatasi Kesulitan Mahasiswa Dalam Menyusun Proposal Penelitian.Yogyakarta. Deepublish.

Nurmailiza Tengku. (2009) Evaluasi Sistem Pengendalian Intern Atas Persediaan Barang Dagangan Pada PT. Sabda Cipta Jaya. Medan

Ristono (2009) Manajemen persediaan : Graha Ilmu. Yogjakarta

Supardi, Y. 2006. Microsoft Visual Basic 6.0 Untuk Segala Tingkat. Elex Media Komputindo. Jakarta

Susanto Azhar (2008) Sistem Informasi Akuntansi Struktur Pengendalian Resiko Pengembangan. Cetakan Pertama. Bandung : Lingga Jaya.

Sutarman (2012) Buku Pengantar Teknologi Informasi. Jakarta: Bumi Aksara.

Yakub (2012) Pengantar Sistem Informasi. Yogyakarta: Graha Ilmu.

M. Sadam ABD Azis Nur, Indah Uly
Wardati, Analisis Dan Perancangan Sistem Informasi Penjualan T-Shirt Pada Unit Dagang (UD) Gojeg Pacitan, Journal Speed - Sentra Penelitian Engineering dan Edukasi - Volume 7 No 1 - 2015, ISSN : 1979-9330 (Print) - 2088-0154 (Online)

Syukri Ali, Arisandy Ambarita, Sistem Informasi Data Barang Inventaris Berbasis Web Pada Kejaksaan Negeri Ternate, IJIS-Indonesian Journal On Information System, Vol 1, April 2016

Semuil Tjiharjadi1, Dony Perdana, Pengembangan Aplikasi Sistem Informasi Distributor Barang PD.D.P. Mandiri, Jurnal SESINDO, Seminar Nasional Sistem Informasi Indonesia, 2 - 4 Desember 2013 